\title{
GÊNERO EM POLÊMICAS: identidades trans nas Women's Colleges dos Estados Unidos da América
}

\author{
Marco Aurélio Máximo Prado \\ Universidade Federal de Minas Gerais - UFMG \\ Antônio Augusto Lemos Rausch \\ Universidade Federal de Minas Gerais - PPGPsi/UFMG
}

\begin{abstract}
Resumo
Este artigo analisa as políticas de gênero em duas faculdades para mulheres nos Estados Unidos da América, compreendendo as prescrições normativas de gênero que articulam a categoria "mulher" na mudança das políticas de admissão destas instituições para a inclusão de estudantes transgênero. Desse modo, analisamos o conteúdo de documentos e entrevistas com membros da administração e estudantes dessas faculdades, e como o debate público sobre a inclusão de estudantes transgênero cria novas questões para a reivindicação política na contemporaneidade, evidenciando a insuficiência da categoria mulher para articular as políticas de gênero. Concluímos evidenciando a importância das instituições separatistas para o contexto estadunidense de violência de gênero nos ambientes educacionais, e como se tornaram, historicamente, espaços de transformação social e formação de ativistas e pensadoras feministas.
\end{abstract}

Palavras-chave: gênero, diversidade sexual, educação, inclusão, women’s colleges.

\begin{abstract}
This article presents the gender politics in two women's colleges in the United States of America, understanding the normative prescriptions of gender articulating the category "women" in the processes of changing the admission policies for the inclusion of transgender students. In this sense, we analyze the content of documentation and interviews with staff and students of these colleges, and how the public debate around inclusion of transgender experiences in educational environments sets new problematics for contemporary political claims, putting some light on the "women" as insufficient category of gender politics. We conclude by arguing the importance of these institutions for the US context of gender violence in educational environments, and how, historically, they have become places for social change and provided education for political activists and feminist thinkers.
\end{abstract}

Keywords: gender studies, sexual diversity, education, inclusion, women's colleges. 


\section{Introdução}

As Women's Colleges (WOC) nos Estados Unidos da América exercem papel importante no enfrentamento das desigualdades de gênero na educação superior do país. Estas escolas surgiram enquanto seminários religiosos no século XIX, logo após a guerra civil e a Revolução Americana, e adotaram, naquele momento, a missão de oferecer às mulheres oportunidades de ensino quando ainda a maioria das escolas de ensino superior privadas no país eram exclusivamente masculinas.

Elas se expandiram pelo país durante o século XX, grande parte relacionada à demanda de força de trabalho feminina na educação e saúde nos períodos de guerra. Atualmente há 37 faculdades para mulheres nos Estados Unidos da América, das quais um seleto grupo se mantém entre as mais prestigiadas escolas privadas de ensino superior no nordeste do país. Essas são conhecidas como as seven sisters, e são Barnard College, Bryn Mawr College, Wellesley College, Smith College \& Mount Holyoke College. Também integraram as seven sisters a Vassar e Radcliffe College, que se tornaram coeducacionais ${ }^{1}$ em 1969 e 1999, respectivamente.

A partir de 2013, as WOC estiveram no centro do debate público sobre discriminação e inclusão no ensino superior estadunidense, quando a estudante transgênero chamada Calliope Wong teve sua inscrição negada na Smith College sob argumento de ter seu sexo referido enquanto masculino no serviço de seguridade social. A repercussão deste caso gerou discussão sobre as exigências de reconhecimento legal da identidade de gênero para ingresso nestas, e culminou na revisão das suas políticas admissionais e na interpelação da categoria mulher para as demandas feministas (Butler, 2016).

O caso trouxe à tona um conflito histórico que ocorre também dentro dos movimentos feministas: como pensar espaços de reivindicação de direitos considerando a insuficiência da categoria "mulher" para nomear experiências de diversidade sexual e de gênero, e da interseção entre gênero, raça, cultura, e várias outras categorias identitárias.

A pergunta "O que é uma mulher para uma faculdade para mulheres?" acaba se materializando como "quem e como define quem são as mulheres?". Nesse sentido, o objetivo principal deste trabalho foi buscar compreender como os diversos atores em tela argumentaram acerca das questões de gênero e quais efeitos nas políticas de inclusão escolar que esse debate contemporâneo está a provocar, uma vez que as reivindicações da identidade "mulher" enfrentam, em seus diferentes contextos, vários impasses a partir da emergência da equivalência de direitos das pessoas trans ${ }^{2}$.

Buscamos evidenciar como as demandas por inclusão social de pessoas trans no contexto atual apontam para uma problematização que coloca no centro da discussão sobre as identidades a referência a categoria “mulher”. Além disso, nosso objetivo é também considerar, a partir da experiência das WOC nos Estados Unidos da América, a importância de questionar a lógica das identidades nas políticas de inclusão. 


\section{Women's College e a mulher como categoria de gênero}

Os primeiros seminários para mulheres se estabeleceram ainda no século XIX. Suas formações primariamente estavam voltadas ao papel das mulheres no ambiente doméstico como esposas e mães nos ideais republicanos e das tradições religiosas protestantes, que, por sua vez, pretendiam a completa utilidade das mulheres na construção do reino de Deus na Terra, e na propagação do evangelho (Sweet, 1985). Mais que somente cursos de etiqueta, os seminários se voltavam à economia doméstica, música, artes visuais e literatura, buscando oferecer uma completa educação moral para as mulheres. Essas formações, cujas alunas eram em sua maioria de estratos sociais altos, proporcionaram também o aumento das possibilidades de casamento através do fortalecimento de uma identidade cultural aristocrática.

No contexto posterior à Revolução Americana, atravessado pela guerra civil e marcado pelo início da Era Progressista nos Estados Unidos, alguns dos seminários para mulheres tiveram seus currículos reformulados para que pudessem oferecer uma educação de qualidade, equiparada aos cursos superiores oferecidos aos homens, no que tange à sua rigidez e ao conteúdo ministrado. A educação superior formal para mulheres surge como uma resposta à demanda de trabalho feminino, principalmente na educação, como professoras, e na saúde, como enfermeiras. Alguns destes cursos se tornaram posteriormente faculdades para mulheres, que passaram a oferecer formação científica e currículos direcionados a atividades de trabalho e artes liberais. Estas instituições adotaram, nesse momento, a missão de oferecer às mulheres oportunidades de acesso à educação superior, quando ainda a maioria das faculdades privadas no país eram exclusivamente masculinas (Harwarth et. al, 1997).

O fortalecimento dos ideais republicanos de igualdade após a guerra civil americana, junto às missões das WOC, permitiu uma aproximação das faculdades para mulheres de alguns movimentos sociais e políticos. Nesse momento, a preocupação dos movimentos de mulheres se voltava para a inclusão feminina em papéis de importância política, social e econômica. A palavra "feminismo" ainda era evitada, devido a sua constante associação ao comunismo, e aos movimentos pelos direitos civis. A ascensão dos movimentos pelo sufrágio demorou mais algumas décadas, apesar de também ter exercido influência no planejamento da educação superior para as mulheres nos Estados Unidos da América (Eisenmann, 2006). Até então, os direitos das mulheres eram pensados a partir de um paradigma de inserção em uma estrutura social e dentro de um projeto de nação, sem que isso significasse pensar criticamente sobre as hierarquias sexuais, e na possibilidade de deslocamentos das identidades femininas.

Durante a primeira metade do século XX, a educação profissional se tornou cada vez mais necessária para a ocupação dos postos de trabalho dentro do país. A crise de 1929, o período entreguerras e a necessidade cada vez maior de dois salários nas famílias americanas - diretamente relacionada aumento da desigualdade social - proporcionou um aumento das taxas de mulheres que tinham ocupações fora do ambiente doméstico e que ocupavam postos de trabalho anteriormente entendidos como masculinos (Eisenmann, 2006). 
A entrada de mulheres em campos científicos e de trabalho anteriormente ocupados por homens fez com que em 1944 elas representassem metade da população de alunos das instituições de ensino superior do país. Contudo, após o fim da segunda guerra, esse movimento desacelerou e ocorreu uma pressão para que as mulheres retornassem ao ambiente doméstico para restabelecer as bases morais e econômicas da nação, e possibilitar aos homens que voltem a ocupar os espaços no mercado de trabalho (Eisenmann, 2006). Naquele momento, muitas das faculdades para mulheres começaram a admitir homens, devido à baixa quantidade de alunas, e por causa disso muitas se tornaram mistas ou fecharam as portas até a década de 1960. Todavia, o número real de mulheres inscritas nas faculdades ainda crescia. (Harwarth et. al, 1997).

A partir de 1960, com as novas articulações políticas dos movimentos de mulheres que surgiram no país extremamente inspiradas nos movimentos de direitos civis, começou a se pensar novas possibilidades de reivindicação para além da criação de leis, implementação das políticas públicas e inserção das mulheres em espaços de poder. Os movimentos feministas se deslocaram dos ideais republicanos em direção às críticas ao patriarcado e as formas de dominação sobre as mulheres. A emergência dos feminismos modernos criou o fundo de uma mudança da compreensão das relações de gênero e, consequentemente, da reivindicação de direitos femininos (Harwarth et. al, 1997). Nas articulações entre os movimentos sociais e educação isso significou novas interpretações e novas funções para as instituições que ofereciam educação superior para mulheres, especialmente no que diz respeito às missões das faculdades single-sex. Menos que proporcionar educação de qualidade, as WOC se tornam também agentes ativos no enfrentamento político das desigualdades entre os sexos na educação e importantes centros de formação de ativistas e teóricas feministas durante o século XX.

A educação ocupa um lugar privilegiado nas disputas políticas, considerando seu caráter transformador social. Por causa disso, ela concentra uma multiplicidade de esforços de redução da desigualdade social (sejam raciais, de gênero, nacionalidade, econômicas, etc.). Nos Estados Unidos, a Lei de Direitos Civis de 1964, e a Emenda Educacional de 1972 representam os principais marcos legais do enfrentamento do preconceito de raça e sexo, respectivamente.

Sendo assim, analisamos o surgimento do conflito ao redor da presença de estudantes transgênero nas faculdades Smith e Mount Holyoke, através das notícias veiculadas em portais da web, das postagens no blog de uma estudante transgênero, dos grupos de alunas e alunos que advogam pela inclusão de estudantes transgênero dentro dos campi, e das falas de estudantes e membros da administração entrevistados. Estrategicamente, aproximamos o conflito ao redor das missões das WOC às disputas e mudanças que ocorreram dentro das Faculdades e Universidades Historicamente Negras (HBCUs) estadunidenses, que, mesmo com a presença de estudantes não-negros nas suas salas de aula, se mantiveram centrais no debate sobre racismo na educação superior do país (Gasman, 2013; Freemark, 2015; Jewell, 2002).

Esta pesquisa investigou a inclusão de estudantes transgênero em duas das principais faculdades para mulheres nos Estados Unidos da América (Smith College e Mount Holyoke 
College), apontando para três objetivos específicos: a) compreender as particularidades históricas das instituições, b) investigar a emergência dos atores e seus argumentos na emergência do conflito indicado, e c) compreender como as diferentes disputas políticas envolvidas nos processos de negociação das novas políticas de admissão interpelam as lógicas identitárias.

A escolha por essas WOC se deu, primeiramente, pela repercussão e importância do caso da estudante Calliope Wong dentro de Smith, uma vez que foi através desse caso que se torna público o conflito entre os diferentes atores e se mobilizam grupos sociais em torno da demanda de inclusão de pessoas trans no sistema escolar feminino e, conjuntamente, do pioneirismo da Mount Holyoke College que, entre as sete irmãs (no momento cinco), foi a primeira a adotar uma política de admissão inclusiva para pessoas transgênero com uma certa rapidez buscando prevenir demandas jurídicas sobre a questão. Dessa forma, tanto Smith como Mount Holyoke College se tornam o centro do debate sobre a categoria "mulher” para se pensar políticas de inclusão institucionais baseadas na diversidade de gênero.

\section{Metodologia}

Na perspectiva de alcançar os objetivos pretendidos, utilizamos diversos procedimentos metodológicos a fim de compreender as complexas questões que foram acionadas quando da primeira recusa das instituições pela admissão de pessoas trans e a emergência do conflito a partir daí. Três etapas foram fundamentais para o aperfeiçoamento metodológico: a) mapeamento de notícias e revisão da literatura, b) entrevistas com estudantes e gestores e, c) análise de documentos e relatórios produzidos pelas instituições.

Recolhemos os materiais de blogs e portais na internet reconfigurando historicamente a emergência da questão pública quando do aparecimento da recusa da admissão da estudante Calliope Wong. Em seguida, ao reconstruir toda informação, recorremos a uma revisão da literatura sobre a emergências das WOC e o impacto na escolarização das mulheres na sociedade estadunidense sobretudo buscando compreender as mudanças que as WOC foram enfrentando nas suas histórias de pensar uma educação feminista.

Munidos desses elementos iniciamos uma preparação para entrevistas com variados atores desse conflito. Divulgamos a pesquisa para o encontro de candidatos/as para entrevistas nos campi das referidas escolas, redes sociais e cafeterias estudantis ao redor, bem como iniciamos o contato com representantes institucionais das duas Faculdades.

Foram realizadas entrevistas presenciais (offline) e online, de acordo com a disponibilidade dos/as entrevistadas com estudantes e egressos que se identificavam como pessoas trans (binárias ou não binárias), bem como com duas representantes institucionais, uma de cada Faculdade. Foram realizadas entrevistas semiestruturadas focadas nos temas da pesquisa. Um roteiro mínimo foi preparado considerando as etapas anteriores (levantamento do acontecimento nas redes sociais e em periódicos científicos). O roteiro de entrevista foi dividido em três: um para estudantes, um para egressos e por último um para gestores institucionais. Basicamente todos eles centram em três momentos, guardadas as 
particularidades: a) histórico dos acontecimentos locais; b) percepções do conflito e c) avaliação dos efeitos positivos e negativos na criação de políticas de inclusão. Foram realizadas três entrevistas semiestruturadas com gestores da administração das faculdades (duas entrevistas de Smith, das quais uma foi realizada com um homem transexual que frequentou a faculdade no fim da década de 1990 e que ocupou o cargo de coordenador de formação docente portanto lidou exatamente com essa discussão junto ao corpo docente da Smith e a segunda com a pró-reitora de graduação, responsável por implementar as políticas de inclusão para as mudanças de admissão bem como consensuar entre estudantes, professores e financiadores como a nova política de admissão deveria ser, e uma de Mount Holyoke, realizada com a reitora da instituição naquele momento que foi responsável pela criação e implementação de respostas institucionais à demanda apresentada por estudantes trans); 6 entrevistas semiestruturadas realizadas com estudantes e egressos das instituições.

Foi importante também o acesso e análise de documentos, particularmente, os relatórios do Grupo de Trabalho da Política de Admissão da Smith College que sintetiza todo o processo de debate interno a partir da emergência do conflito e os relatórios com as novas políticas de admissão adotadas por ambas as instituições, bem como a Emenda Educacional de 1972. Logo após a coleta, transcrição e categorização temática de unitermos de todo material coletado, iniciamos uma análise de conteúdo desses materiais, entendendo, com auxílio das teorias de gênero como performatividade (Butler, 2016), de qual maneira as diferentes atrizes e atores nas WOC produzem, materializam e disputam noções de gênero.

A centralidade do debate no momento da admissão se deu em razão da Emenda Educacional de 1972, referente ao Ato de Educação Superior dos Estados Unidos da América, de 1965. Esta emenda ficou conhecida pela inclusão do seu nono título, que estabelece normativas sobre a não-discriminação de gênero dentro das faculdades e universidades que são beneficiadas pelos fundos federais para a educação, e é vista como um seguimento da Lei de Direitos Civis de 1964. A partir deste título, é vetada a discriminação em função de sexo pelas instituições de ensino superior, com algumas exceções, sendo uma delas o momento de inscrição nas faculdades e universidades que historicamente se propuseram a oferecer educação especializada para somente um sexo. Por causa disso, mesmo antes da mudança das políticas de admissão, já haviam pessoas que se identificavam enquanto transgênero ou queer em Smith e Mount Holyoke, grande parte destas que iniciaram seus processos de transição de gênero após a entrada no ensino superior.

\section{Resultados e discussão}

A explosão da discussão pública sobre a inclusão de estudantes trans nas WOC ocorreu grande parte em função da articulação da estudante Calliope Wong, em 2012, num microblog na rede social Tumblr. (Trans Women @ Smith, 2012) Calliope, que se identificava enquanto uma garota transgênero, dizia dos problemas e exclusões que a política adotada até então pela faculdade Smith, implicava para as pessoas como ela. Ela se propôs a analisar rapidamente essas implicações práticas, e argumentou que a exigência da faculdade do reconhecimento 
legal para a admissão das estudantes transgênero era impossivelmente alta, considerando que estas, em média, estariam se inscrevendo nas faculdades e universidades no último ano do ensino médio, e que, por exemplo, para ser reconhecida enquanto fêmea (sic) em sua certidão de nascimento no estado em que vivia (Connecticut), ou no estado de Massachusetts, onde se localizava a Smith College, ela deveria ter realizado um procedimento de vaginoplastia. E que, além de notoriamente caros e de acesso dificultado, esses procedimentos não necessariamente são desejados por ela ou por outras mulheres trans.

Calliope então entrou em contato com a decana responsável pela triagem das inscrições para saber como proceder em sua inscrição na faculdade. Dois meses depois, em seu blog, ela publica a resposta recebida da decana: "Parece [...] que se seus professores se referirem a você nos termos que você sugeriu, todos os seus pronomes serão femininos e então serão consistentes com o que Smith espera”. Ela prosseguiu com a inscrição, e alguns meses depois, recebeu a resposta de que mesmo com as exigências cumpridas, e após ter enviado o formulário pela segunda vez, por causa de uma inconsistência na primeira tentativa, teve sua admissão negada. A decisão foi baseada em como seu sexo foi referido no Free Application for Federal Student Aid (FAFSA), um serviço de seguro e financiamento requerido para o ingresso de estudantes nas instituições de ensino superior privadas.(Trans Women @ Smith, 2013)

[...] no despertar de mudanças sociais, uma estudante em particular se inscreveu em Smith, era uma mulher trans com alguns marcadores masculinos em seus materiais, e nossa política era, na época, que sua identidade enquanto mulher deveria ser constantemente refletida em todos os aspectos da inscrição. Essa era a política que tivemos durante quinze anos, quando essa questão surgiu inicialmente no campus. [Por causa dela] nós retornamos aquela inscrição [...] nós estávamos de certa maneira sob o olhar público, na frente de outras faculdades para mulheres, mesmo que elas também estivessem experimentando algumas destas questões. Eu estive em Smith por quinze anos, então eu posso dizer que "consistentemente identificada enquanto mulher" foram meus termos, e originalmente não era uma política formal, mas com o passar dos anos, acabou se formalizando, enquanto outras mudanças legais também aconteciam. (A., gestora na Smith College, 2015)

A repercussão deste caso dentro de Smith gerou mobilizações por parte de estudantes para um esclarecimento das políticas de admissão. As notícias sobre os protestos de alunos e alunas repercutiram entre sites de organizações que advogam por direitos LGBT (Gay \& Lesbian Alliance Against Defamation - GLAAD), em alguns veículos de mídia, como o New York Daily News, e The Huffington Post, um popular portal de notícias e comentários na internet. Iniciaram, então, articulações para a mudança das políticas de admissão entre as várias faculdades de mulheres ao redor dos Estados Unidos. A exemplo disso, dentro da Mount Holyoke College, se organizou a Open Gates, uma organização de estudantes que buscava a completa inclusão de mulheres trans no campus. O grupo começou a se articular durante o primeiro semestre daquele ano ao redor da necessidade de uma mudança cultural e 
das políticas de admissão na faculdade. Já dentro de Smith, foi criado um grupo de estudos para a análise da Política de Admissão da faculdade, onde se reuniam mensalmente membros da comunidade interna para buscar materiais de pesquisadores na área e dialogar para a criação de proposições ao conselho de admissão da faculdade.

Dentro da Mount Holyoke College, toda a negociação ao redor da política de admissão se deu interna à administração, e foi centrada na figura da até então presidenta da faculdade. Apesar de haver, com clareza, uma movimentação estudantil para revisão da política, e do clima dentro e fora do campus estar favorável à mudança, esse processo não foi protagonizado pelas ações do corpo discente e se deu no período de recesso escolar.

[...] Houve uma reunião, então fomos embora durante o verão, de certa maneira nos separamos (se referindo à organização de estudantes). Então, na convocação do outono, que é nossa cerimônia de boas-vindas no início do ano, a presidente, Lynn Pasquerella, anunciou que agora estamos admitindo mulheres trans! [...] essa primeira reunião aconteceu na primavera de 2014, nós deixamos o campus, e planejamos nos encontrar novamente para conversar e continuar trabalhando durante o outono, mas quando chegamos a mudança da política aconteceu. Nenhum estudante tinha se organizado ainda, então não foi uma mudança pressionada por estudantes, foi completamente do nada. Nós nem fazíamos ideia de que a administração estava conversando sobre isso, não sabíamos que a presidente estava considerando a ideia [...] Nós não fazíamos ideia de que ela sequer sabia o que significava transgênero. [...] Nós nos surpreendemos. (B., estudante de Mount Holyoke, 2015)

A preocupação da presidenta era de que, por envolver diferentes membros da faculdade, distintos interesses pudessem ser conflitantes na alteração das políticas admissionais. As relações com doadores, os conselhos e decanos, e também as famílias das/dos estudantes foi primordial para que a nova política fosse aprovada e anunciada de maneira a não causar impactos negativos na instituição.

A grande questão para nosso conselho foi "Por que temos de ser a primeira? Por que temos de ser a primeira entre as Sete Irmãs? Por que não podemos esperar e ver o que todas irão fazer?" Porque eles estavam muito preocupados com o risco para nossa reputação, e o que essa mudança poderia significar. [...] Finalmente, tudo acabou indo em direção à "nós falamos em nunca temer a mudança, que queremos encontrar, encarar, abraçar, e liderar a mudança, então seria hipocrisia de nossa parte não sermos líderes neste tópico. (ex-presidenta da Mount Holyoke College, 2015).

Em Smith, a escolha pela criação de um grupo de estudos para discussão das políticas de admissão levou o debate por um caminho diferente. Dentro desse grupo, formado por membros da faculdade e uma parcela de estudantes, não havia consenso sobre qual deveria ser a política adotada pela faculdade. Ocorriam debates constantes nos processos de construção das duas propostas que seriam apresentadas ao conselho da administração, que 
seria responsável por eleger a nova política de admissão da faculdade. A presença, ou nãopresença, de homens trans dentro da faculdade foi objeto constante de disputa política interna e as discussões ocorriam de maneira fervorosa, como relata uma administradora e um administrador da faculdade (que se identificava como homem transexual).

Tanto em Mount Holyoke, como em Smith, a preocupação com as relações com os doadores foi constante no processo de elaboração das novas políticas de admissão. Enquanto instituições privadas, as faculdades para mulheres dependem das doações para captação de recursos para seu desenvolvimento, e doadores são, em sua maioria, ex-alunas e alunos, familiares de estudantes ou pessoas e organizações que se identificam nos objetivos de uma educação para mulheres.

Portanto, as novas políticas de admissão não poderiam gerar impactos negativos para a captação de recursos e no recrutamento de estudantes. Segundo relatam as pessoas entrevistadas em Smith, a política adotada foi bem recebida entre o grupo de doadores, e a antiga presidente da Mount Holyoke College relata que o ano que prosseguiu o anúncio a política de admissão foi o maior ano de captação financeira da faculdade, e ter sido pioneira entre as Sete Irmãs acabou por gerar uma boa publicidade para a instituição.

Minha percepção é de que a base-ativa de doadores está, provavelmente, nas classes entre 70' e 80'. Essas são as pessoas que estão, atualmente, fazendo fortunas. Minha percepção é de que esse grupo é mais conservador quanto às questões trans. Quando você pensa no movimento de mulheres, como um movimento em geral, há muita tensão entre as feministas da segunda onda e pessoas trans. Então, eu acredito que isso, que vemos em Smith, seja um reflexo da sociedade em larga. [...] Smith, além de uma instituição de educação, é um negócio. (gestor e ex-aluno da Smith College, 2015)

A multiplicidade de atores e atrizes nos processos de mudança proporcionou negociações entre esses agentes, e disputas por suas noções acerca do que é ser mulher, da missão dessas Faculdades e também de seus interesses econômicos e políticos. Adotar políticas discriminatórias de gênero poderia, no futuro, acarretar em consequências jurídicas para as instituições, e a rápida emergência das mobilizações sociais e repercussão negativa colocaria em risco suas reputações políticas como escolas de ensino superior. O problema em questão se tornou como incluir as experiências dissidentes das normativas de gênero dentro de instituições que tomam como premissa uma existência cissexista binária.

Havia discussão também. Incluiremos homens trans, mulheres trans... e então discutimos sobre o que era dissidência de gênero... Você pode imaginar, quando conheceu ele [T.], porque escolhemos ele. Foi uma decisão óbvia. Mas eu te digo, isso resultou numa renúncia por parte de um dos membros, que sentiu que essa era uma decisão errada, que não poderiam ter discussões sinceras. Isso foi difícil, mas eu não acredito que o processo teria sido tão forte como foi se essa voz não tivesse existido. Foi absolutamente, ao meu ver, a decisão correta. A troca entre esses dois indivíduos foi de muito auxílio para o trabalho daquele grupo, e para 
a compreensão dele. No final de tudo, aquele era um grupo que estudava por muito tempo e muito intensamente, se encontravam e discutiam partindo de pontos completamente diferentes e conseguiram pensar em uma mesma proposta, com diferentes conclusões, mas todas vozes, ao meu ver [...] foram ouvidas, $e$ todos os indivíduos foram respeitados durante o processo, mesmo com suas desavenças. (A., gestora na Smith College, 2015)

É importante destacar que antes da aprovação das novas políticas de admissão, não haviam políticas de exclusão formal de mulheres transgênero em Smith e Mount Holyoke. As inscrições de mulheres trans eram consideradas pelas faculdades, mas para isso, ao se inscrever deveria ter completo reconhecimento legal de sua identidade. Não se tratava de uma política de banimento, mas de uma dinâmica de exclusão, causada pelas exigências burocráticas da faculdade para essas alunas.

Uma das coisas que os atos estudantis estavam mostrando é que a política de admissão estava de fato excluindo mulheres trans, mesmo que ainda dissesse "Suas inscrições são bem-vindas", porque se algum dos documentos não estivessem coerentes, as inscrições das pessoas não seriam lidas, e isso era praticamente excluí-las do processo. Mesmo assim nós já tivemos uma mulher trans como aluna, que disse publicamente sobre o assunto. Então, não está errado afirmar que já há mulheres trans em Smith advogando nesses movimentos. Ainda assim, ela era uma aluna transferida, ela esteve tempo fora, e tinha todos os recursos para regularizar sua documentação antes de se inscrever em Smith. (gestor e ex-aluno da Smith College, 2015)

Tanto na solução apresentada por Smith, que desconsidera como aptos para a inscrição pessoas não-binárias e homens transgênero (mesmo que estes estejam no campus, pois, após o momento da admissão estes alunos não podem sofrer atos discriminatórios por parte das instituições, e muitos iniciam seu processo de transição dentro das Faculdades), ou na solução apresentada pela Mount Holyoke College, que estabelece que as pessoas não-binárias estão aptas à inscrição, desde que suas identidades incluam uma feminilidade, o que se apresenta é um ideal normativo de gênero dentro dos seus funcionamentos.

Judith Butler (2016) mostra como a identidade se tornou um problema para a teoria e ativismo feminista, de maneira que interior a ele começaram a surgir questionamentos sobre os critérios que definiam quem eram "O Sujeito” da política do feminismo, e quais outros “Sujeitos” não apareciam nas narrativas políticas hegemônicas.

Gêneros “inteligíveis” são aqueles que, em certo sentido, instituem e mantêm relações de coerência e continuidade entre sexo, gênero, prática sexual e desejo. Em outras palavras, os espectros de descontinuidade e incoerência, eles próprios só concebíveis em relação a normas existentes de continuidade e coerência, são constantemente proibidos e produzidos pelas próprias leis que buscam estabelecer linhas causais ou expressivas de ligação entre o sexo biológico, o gênero 
culturalmente constituído e a "expressão" ou "efeito" de ambos na manifestação do desejo sexual por meio da prática sexual. (Butler, 2016, n.p.)

Compreender as normas de gênero através da inteligibilidade possibilita pensar a insuficiência da categoria “mulher” para inclusão de corpos não-heterossexuais e cisgênero nos movimentos sociais e dentro das WOC. Assim, podemos nos perguntar "quem são as mulheres das Faculdades para Mulheres?”, “o que significa 'mulher’ para uma Faculdade para Mulheres?”, e “quem pode definir o que/quem é 'mulher'?”. A crítica do caráter universalizante desta categoria, que historicamente esteve atribuída às mulheres brancas, de classe média, cisgênero e heterossexuais nos movimentos feministas, traz a dinâmica da interseccionalidade das relações de poder para dentro das women’s colleges.

Se alguém "é” uma mulher, isso certamente não é tudo o que esse alguém é; o termo não logra ser exaustivo, não porque os traços predefinidos de gênero da “pessoa” transcendam a parafernália específica de seu gênero, mas porque o gênero nem sempre se constituiu de maneira coerente ou consistente nos diferentes contextos históricos, e porque o gênero estabelece interseções com modalidades raciais, classistas, étnicas, sexuais e regionais de identidades discursivamente constituídas. Resulta que se tornou impossível separar a noção de "gênero" das interseções políticas e culturais em que invariavelmente ela é produzida e mantida. (Butler, 2016, n.p.)

A exclusão das narrativas transgênero das missões históricas das faculdades para mulheres, e das estudantes dos seus processos de admissão podem ser compreendidas como dinâmicas de preconceito institucional. Prado, Martins e Tolentino (2012) argumentam como a homofobia (neste caso, transfobia) é uma prática que garante a manutenção e gestão dos corpos através de um ideal heteronormativo, sem que necessariamente ocorram práticas de violência contra um indivíduo. Nesse sentido, a noção de preconceito de gênero não se refere à violência contra pessoas (ou identidades) pertencentes à um grupo, mas sim à hierarquização institucional que torna inteligível os corpos dentro de uma comunidade através da heteronorma, que estabelece coerência entre corpo, gênero/sexo, prática sexual e identidade. Assim, as experiências transgênero estariam nos limites da normatividade sobre os corpos generificados, pois deslocariam esta coerência para uma posição até agora "ininteligíveis" em termos heterossexistas.

O desafio para estas instituições, interpelado por estas experiências, é repensar as suas próprias missões e noções de "mulher" fora de um ideal heterossexual (e cissexista). Essa questão também é deslocada a um outro campo: como é possível, dentro do feminismo, pensar uma luta pela igualdade de gênero sem um ideal de "mulher" que se proponha universal. Butler (2016), se questiona sobre como dentro do movimento feminista uma indeterminação do conceito de gênero parece causar uma ansiedade, ou medo, de um fracasso da reivindicação política. Mais adiante na obra, ela também se pergunta se a própria construção da categoria mulheres também não seria uma regulação ou reiteração das normas de gênero. O que foi relatado na fala de estudantes com quais foram feitas as entrevistas sobre 
suas experiências nas faculdades para mulheres (enquanto pessoas transgênero), foi como as lógicas das instituições reproduziam as regulações normativas de gênero, e como dentro das salas de aula, dormitórios, espaços administrativos, etc., uma série de deslegitimações de suas identidades ocorriam, desde o não-respeito ao uso dos pronomes e nomes preferidos pelos professores, às dificuldades de acesso ao serviço de saúde, hormonização, e distribuição arquitetônica dos banheiros nos prédios.

A pressuposição de que todo o corpo estudantil é composto por mulheres acaba por também ser uma forma de regulação de gênero: diz como as pessoas devem agir, e consequentemente ser um gênero dentro das faculdades. As políticas de admissão, mesmo as que se deram após a discussão sobre a presença de estudantes transgênero, parecem atuar enquanto uma invocação performativa de uma feminilidade normativa. É como se ela dissesse: "Esta é uma faculdade para mulheres, comporte-se como uma mulher!". Ainda assim, a inclusão das mulheres que integram outras minorias sociais foi uma pauta presente nas instituições desde suas fundações (Harwarth, et. al., 1997; Horowitz, 1984), mas se intensificou a partir da segunda metade do século XX.

Mesmo que as novas políticas de admissão nestas faculdades para mulheres se atentem à auto identificação de gênero, o processo político e repertório argumentativo à favor desta inclusão se aproximou das construções sobre identidade de gênero da medicina e psiquiatria. Isso se evidencia nas políticas que foram adotadas na Smith College após a mudança: a exigência de ser consistentemente identificada como mulher agora se apresenta na exigência da autoafirmação de gênero surgir de um lugar identitário cristalizado, rígido e essencializado. Exigência que também aparece na noção das experiências de gênero nãobinárias de Mount Holyoke, onde se permite a identificação como pessoa não-binária, desde que suas identidades incluam “mulher”. Assim, esse não-binarismo só é inteligível dentro dos limites da feminilidade. As duas medidas exigem que as identidades transgênero ainda se afirmem nos termos do binarismo de gênero, as enquadrando novamente a partir de um ideal heterossexual.

O gênero continuou sendo pensado como expressão essencialmente identitária e cristalizada, onde a construção das corporeidades trans fora desses termos psicologizantes, que caminham a direções opostas das expectativas de feminilidade tradicional, não são pautadas dentro das políticas de admissão (e se evidenciam na inexistência das políticas de permanência estudantil). Os relatos de estudantes apontam uma reprodução das dinâmicas das relações de gênero dentro das faculdades para mulheres, e fragilizam a resposta separatista enquanto estratégia única de enfrentamento da desigualdade. Mais adiante, ao pensar as dinâmicas de exclusão de maneira interseccional, precisaremos compreender como as diferentes condições econômicas, raciais, corporais e culturais estão presentes dentro das instituições de educação superior e afetam a permanência e trajetória de estudantes que não se enquadram nas heteronormativas educacionais, para além do que se entendeu historicamente como "gênero".

Nas falas de uma estudante que preferiu não consentir à gravação de entrevista, também surge uma inquietação ao redor das expectativas sobre as estudantes transgênero serem também expectativas de feminilidade branca e de classes média-alta. As faculdades para 
mulheres, apesar de se proporem à inclusão de mulheres na educação superior, ainda têm taxas altas, e a grande maioria de seu corpo docente e discente integram estratos sociais mais privilegiados econômica e racialmente. Sendo assim, a inclusão de estudantes transgênero nestas instituições ainda precisa ser atravessada por categorias de classe e raça, bem como outras categorias interseccionais.

Então, esta é uma coisa que estou perguntando... Enquanto movimentos sociais, temos expandido e tentado encontrar maneiras de sermos interseccionais, estaríamos indo em direção a reivindicações de pautas que nos afetam, ao invés de reivindicações identitárias? (gestor e ex-aluno da Smith, 2015)

Uma estratégia interessante para pensar uma educação que enfrente estas desigualdades históricas sem adotar um essencialismo identitário foi aquela adotada pelas Faculdades e Universidades Historicamente Negras nos Estados Unidos. Apesar de nunca terem admitido somente estudantes negros, essas escolas ainda assim se consolidaram e se tornaram instrumentos importantes de enfrentamento das desigualdades raciais no país, e formaram grande parte dos médicos, advogados, dentistas professores e outros profissionais negros durante o século XX (Freemark, 2015), além de também serem importantes no enfrentamento de outras desigualdades raciais, de gênero, religião e sexualidade, com presença significativa de uma população diversa dentro de suas salas de aula (Gasman, 2013).

Criadas após o fim da guerra civil nos Estados Unidos da América, estavam constantemente associadas a instituições religiosas que tinham apoio financeiro de filantropos brancos que buscavam possibilitar o acesso à educação formal para pessoas negras no sul dos Estados Unidos. Os interesses missionários dessas escolas eram de conversão das pessoas negras ao cristianismo e de preparação para trabalhar nos setores industriais da nova economia do país (Gasman, 2013). As primeiras escolas, inicialmente, proviam educação básica direcionada para cargos de pastores, fazendeiros e professores. Com o passar dos anos, essas instituições educacionais passaram a fornecer educação para engenheiros, médicos, advogados, legisladores e, por fim, presidentes de faculdades.

Na primeira metade do século XX houve um crescimento e expansão das faculdades historicamente negras. Elas tiveram grande quantidade de alunos notáveis e formaram profissionais competentes em diversas áreas e se tornaram centros de ensino e pesquisa referenciados. Entretanto, quando o processo de integração iniciou-se nos Estados Unidos com a Lei dos direitos civis de 1964, o número de estudantes que ingressaram nas Historically Black Colleges and Universities começou a cair. Por causa disso, muitas faculdades começaram a perder o apoio federal e a fechar suas portas (Freemark, 2015). Nesse mesmo período, o corpo estudantil destas instituições começou a se diversificar, apesar de nunca terem adotado políticas admissionais discriminatórias (Jewell, 2002), havendo também um aumento significativo da disparidade entre homens e mulheres nestes campi, a ponto de que, em algumas dessas faculdades, o número de mulheres nos programas de graduação chega a ser duas vezes maior que de homens (Gasman, 2013). 
A admissão de estudantes de grupos étnico-raciais não-negros nas HBCUs dos Estados Unidos ocorreu sem que essas faculdades prejudicassem o cumprimento de suas missões. Elas continuaram no enfrentamento da desigualdade racial no acesso à educação, sem desconsiderar outros grupos também desprivilegiados no acesso ao ensino superior. A presença significativa de pessoas brancas dentro dos cargos de gestão e docência foram entendidos como atos de suplemento aos esforços de pessoas negras para a implementação da diversidade. Houve também um distanciamento, principalmente em função dos movimentos de apreciação da cultura negra a partir da metade do século XX, das crenças e moralidades da classe alta e branca presente na fundação dessas escolas, possibilitando o um estímulo de divulgação de autoras e autores negros e não-brancos nas produções acadêmicas, bem como incentivando uma produção científica antirracista. (Jewell, 2002)

Semelhantemente, em Smith e Mount Holyoke sempre houve presença de homens cisgênero como administradores, professores, e inclusive recentemente, como alunos. As duas faculdades passaram a integrar em 1999 o Five College Consortium, um consórcio entre cinco faculdades do nordeste dos Estados Unidos, sendo a maior delas a Faculdade Amhrest (que integra a Universidade de Massachussets). Entre as cinco instituições, Smith e Mount Holyoke são as únicas de ensino exclusivamente voltadas para mulheres, ou seja, alunos que se identificam como homens cisgênero das outras faculdades tem a possibilidade de transitar dentro dos câmpus e frequentar algumas salas de aula.

Uma das reações reacionárias à inclusão das mulheres trans dentro das faculdades para mulheres, foi, e ainda é, um medo ou pânico do que a condição de um corpo designado "masculino" signifique ao transitar dentro dos espaços femininos, como se esse corpo sempre representasse a potencialidade de um corpo violento, muitas vezes estuprador. Nanney (2017) analisou como estudantes apontavam, após as mudanças das políticas admissionais, pensamentos excludentes por parte de certos grupos feministas dentro dos câmpus (frequentemente denominados $T E R F^{3}$ ). Estes grupos insistiam que a inclusão das mulheres trans (a quem se referem como homens) nos espaços feministas seria uma ameaça às mulheres (cisgênero). Durante e após o processo de mudança das políticas de admissão, foram relatadas nas entrevistas a presença de manifestações de pânico moral dentro das faculdades, por partes do corpo estudantil, docente e administrativo.

Gayle Rubin (1982) apresenta o pânico moral ao redor de algumas comunidades eróticas, e como ele mobiliza ações políticas de repressão e marginalização de travestis, homossexuais, trabalhadoras/es sexuais, pessoas soropositivas, usuários de drogas entre outras. "As atividades sexuais costumam funcionar como significantes de receios pessoais e sociais com os quais elas não têm relação intrínseca alguma" (Rubin, 1982, p.109). A partir dos estigmas sociais atribuídos a essas populações na hierarquia social, são acionadas a mídia, as instituições sociais e jurídicas para a defesa da saúde, das mulheres, das crianças e da moralidade. O pânico canaliza as ações políticas e de transformação social, culpabilizando populações marginalizadas e restringindo sua liberdade. Alguns exemplos são o policiamento das comunidades homossexuais na epidemia de HIV/AIDS, as campanhas contra adoção por casais não-heterossexuais, e recentemente, a oposição ao reconhecimento dos direitos da população trans e queer, sob justificativa de combate à "Ideologia de gênero". 
Contudo, foram as próprias noções de corpos essencialmente masculinos ou femininos que se tornaram problemas para as missões históricas que agora são questionadas através das críticas da produção do sexo biológico como fundamentais para suas existências. Essas instituições, mesmo com a presença significativa de homens em seus corpos, ainda tiveram protagonismo na produção feminista que historicizou as violências de gênero, até então naturalizadas, deslocando-as para o campo das relações sociais.

Quando grupos que se autodeclaram feministas direcionam seus ataques às populações socialmente marginalizadas (neste caso pessoas transexuais), suas argumentações se articulam com um pânico de fundamentação moralista que reafirma as hierarquias de gênero que se propuseram a criticar inicialmente. Este pânico não considera que a entrada de homens e mulheres transexuais, bem como outras pessoas que não se identificam como cisgênero nas faculdades para mulheres não resultam na falha de suas missões históricas de garantia de educação para mulheres, mas sim numa ampliação do que se entende como gênero, identidade e da função dessas instituições frente à desigualdade de gênero e da promoção do respeito à diversidade. Mulheres, homens trans, e pessoas genderqueer ao ingressarem no espaço educacional das faculdades para mulheres se aproximam justamente através de suas experiências de gênero, parcialmente, compartilhadas entre si enquanto minorias sexuais. A reiteração dos estigmas de obscenidade e violência atribuídos à essas populações é uma estratégia discursiva que desloca o argumento da inclusão de pessoas trans nos ambientes educacionais para a segurança das mulheres cisgênero nos banheiros e dormitórios.

A presença crescente de pessoas que não se identificam como mulheres (cisgênero) dentro das WOC, e as demandas constantemente levadas por estes estudantes à administração dessas escolas apontam a necessidade de pensar a inclusão das populações trans nestas faculdades para além de “abrir os portões”. Apesar das Faculdades para Mulheres oferecerem ambientes relativamente mais favoráveis à diversidade de identidades de gênero que as instituições coeducacionais (Freitas, 2017), ainda é necessário colocar no horizonte outras políticas afirmativas para redução da discriminação e preconceito, bem como garantir a estudantes destes grupos as condições mínimas para suas existências (como o acesso à saúde integral, moradia, alimentação, uso dos banheiros, enfrentamento do preconceito, etc.). “Eles nos fizeram reconhecer que nem todo mundo aqui se identifica enquanto mulher" (expresidenta da Mount Holyoke College, 2015).

Mesmo assim, a resposta separatista das faculdades para mulheres ainda é importante para o contexto estadunidense de violência de gênero dentro das instituições coeducacionais, especialmente no que diz respeito ao enfrentamento do assédio e violências sexuais. Enquanto dentro das faculdades para mulheres os índices de violência sexual são baixos (de acordo com as falas da administração e estudantes coletadas), 19\% das estudantes de graduação americanas relatam já terem sofrido tentativas ou atos consumados de violência sexual após o ingresso nas instituições de ensino superior (Krebs et. al, 2007). Mas seria a separação das mulheres em ambientes onde, teoricamente, estariam apartadas de homens (cisgênero) que permitiria uma educação feminista? Não teriam essas faculdades adotado a missão de “oferecer uma educação de qualidade para mulheres” exatamente por reconhecer 
que uma educação separatista, unicamente, não garantia que as mulheres tivessem acesso à educação de qualidade?

Não surpreendentemente, essas faculdades formaram uma geração de importantes ativistas, intelectuais, artistas e cientistas mulheres. Entre suas alunas notáveis se encontram Betty Friedan (filósofa feminista), Margaret Mead (antropóloga), Gloria Johnson-Powell (ativista de direitos civis); e outras importantes figuras políticas como as ex-Secretárias de Estado dos EUA, Hilary Clinton e Madeleine Albright, e até mesmo lideranças internacionais, como a ex-primeira ministra paquistanesa Benazir Bhutto (graduada em 1973 pela Radcliffe College).

As WOC ainda sucedem em fornecer recursos para segurança e formação de mulheres, de maneira que suas alunas têm, em média, melhores desempenhos profissionais, maior retorno financeiro e reconhecimento intelectual, além de diferenças significativas no comportamento e atitudes igualitárias que nas faculdades coeducacionais (Smith, 1990; Miller-Bernal, 1993; Riordan, 1994; Smith, Wolf \& Morrison, 1995;). Mas isso parece se relacionar muito mais a como são pensados os paradigmas educacionais, à como são treinadas professoras e professores, administradoras e administradores que necessariamente com a composição do corpo estudantil em função do sexo.

As experiências trans na educação evidenciam que ela representa mais que a formação acadêmica ou técnica. As reivindicações pela entrada e permanência de estudantes trans nas WOC reafirmam que a educação é um espaço para construção de si e do gênero, de reconhecimento e transformação social, e de disputas políticas. Enquanto organizações educacionais que prezam pela transformação social e política, as WOC agora se veem frente a uma diversidade das experiências de gênero interseccionais, e retomaram suas missões históricas para pensar a mudança das políticas admissionais para inclusão de estudantes transgênero, e também a criação de novas políticas de ação afirmativa dentro dos campi para que se tornem, também, espaços de formação para uma nova geração de intelectuais, artistas e cientistas não somente femininas (e cisgêneras), mas também transgêneras, masculinas e genderqueer.

\section{Notas}

1. Termo utilizado para se referir às instituições que não fazem distinção de gênero em seus processos de admissão.

2. Utilizar-se-á a referência a travestis e transexuais a denominação “pessoas trans”.

3. TERF - Trans Exclusionary Radical Feminism (Trad.: Feminismo Radical Trans Excludente), é um termo utilizado para se referir a pessoas e grupos que se autodenominam feministas e que reproduzem, inclusive teoricamente, pensamentos de ordem transfóbica. É, muitas vezes, entendido como um insulto, devido ao tom pejorativo.

\section{Referências Bibliográficas}

BENNETT-SMITH, Meredith. Smith College Rejects Female Transgender Student Calliope Wong; Applicant Ruled 'Male' By Admissions. The Huffington Post. Disponível em: <https://www.huffpostbrasil.com/ entry/smith-college-transgender-calliope-wong_n_2920845> Acesso em: 10 out. 2018. 
BUTLER, Judith. Problemas de Gênero: feminismo e subversão da identidade. 10. ed., Rio de Janeiro: Civilização Brasileira, 2016. n.p.

EISENMANN, Linda. Higher Education for Women in Postwar America, 1945-1965. Baltimore: John Hopkins University Press, 2006, 296p.

ESTADOS UNIDOS DA AMÉRICA. Public Law 92-318. 23 de junho de 1972. Education Amendments of 1972. Disponível em: <https://catalog.archives.gov/id/7455551> Acesso em: 10 out. 2018.

FIVE COLLEGE CONSORTIUM. Academics. 2017. Disponível em: $<$ https://www.fivecolleges.edu/academics> Acesso em: 10 out. 2018.

FIVE COLLEGE CONSORTIUM. Five College Women's Studies Research Center. Disponível em: $<$ https://www.fivecolleges.edu/fcwsrc> Acesso em: 10 out. 2018.

FREEMARK, Samara. The history of HBCUs in America. American Radioworks. Disponível em: $<$ http://www.americanradioworks.org/segments/hbcu-history/> Acesso em: 10 out. 2018.

GASMAN, Marybeth. The changing face of historically Black colleges and universities. Penn Center for Minority Serving Institutions, University of Pennsylvania, 2013. Disponível em: $<$ https://repository.upenn.edu/gse_pubs/335/> Acesso em: 10 out. 2018

GREENE, David A. The Women's Movement and the Politics of Change at a Women's College. Nova Iorque e Londres: Routledge Falmer, 2004, 155pp.

HARWARTH, Irene. et al. Women's Colleges in the United States: History, Issues, and Challenges. Washington: Government Printing Office, 1997.

HEFFERNAN, Dani. Advocates Urge Smith College To Stop Discriminating Against Trans Women. GLAAD. 24 mar 2013. Disponível em: <https://www.glaad.org/blog/advocates-urge-smith-college-stopdiscriminating-against-trans-women> Acesso em: 10 out. 2018.

HOROWITZ, Helen Lefkowitz. Alma mater: Design and experience in the women's colleges from their nineteenth-century beginnings to the 1930s. New York: Alfred Knopf, 1984.

JEWELL, Joseph O. To set an example: The tradition of diversity at historically Black colleges and universities. Urban Education, Nashville, TN, Vanderbilt University, v. 37, n.1, pp.7-21, jan. 2002. Disponível em <http://dx.doi.org/10.1177/0042085902371002> Acesso em: 10 out. 2018.

KREBS, Christopher P., et. al. The Campus Sexual Assault (CSA) Study. Disponível em $<$ https://www.ncjrs.gov/pdffiles1/nij/grants/221153.pdf> Acesso em: 10 out. 2018.

MILLER-BERNAL, Leslie. Single-Sex versus Coeducational Environments: A Comparison of Women Students' Experiences at Four Colleges. American Journal of Education, Chicago, IL, The University of Chicago Press, v. 102, n. 1, Nov. 1993, pp.23-54. Disponível em <https://www.jstor.org/stable/1085694> Acesso em: 10 out. 2018.

MOUNT HOLYOKE COLLEGE. Admission of Transgender Students. Disponível em $<$ https://www.mtholyoke.edu/policies/admission-transgender-students\#q1> Acesso em: 10 out. 2018.

NANNEY, Megan. “I'm Part of the Community, Too": Women's College Alumnae Responses to Transgender Admittance Policies. In: DEMOS, Vasilikie; SEGAL, Marcia Texler. (Org.) Advances in Gender Research: Gender Panic, Gender Policy. v.24. Emerald Publishing Limited, pp.133-154.

PRADO, Marco Aurélio Máximo; MARTINS, Daniel Arruda; TOLENTINO, Leonardo Lima Rocha. O litígio sobre o impensável: escola, gestão dos corpos e homofobia institucional. Bagoas - Estudos gays: gêneros e sexualidades, v. 3, n. 04. Natal, 27 nov. 2012. Disponível em: <https://periodicos.ufrn.br/bagoas/article/view/2304> Acesso em: 10 out. 2018.

RIORDAN, Cornelius. The Value of Attending a Women's College: Education, Occupation, and Income Benefits. The Journal of Higher Education, Columbus, OH, Ohio State University, v.65, n.4, jul-ago 1994, pp.486-510. Disponível em: <https://www.jstor.org/stable/2943857> Acesso em: 10 out. 2018. 
RUBIN, Gayle. (1982). Pensando o sexo: notas para uma teoria radical da política da sexualidade. In: (2017). Políticas do sexo. São Paulo: Ubu. pp.62-128.

SMITH, Daryl G.; WOLF, Lisa E.; MORRISON, Diane E. (1995). Paths to Success: Factors Related to the Impact of Women's College. The Journal of Higher Education, Columbus, OH, Ohio State University, v. 66, n.3, maio-jun 1995, pp.245-266. Disponível em: <https://www.jstor.org/stable/2943891> Acesso em: 10 out. 2018.

SMITH, Daryl G. Women's Colleges and Coed Colleges: Is There a Difference for Women? The Journal of Higher Education, Columbus, OH, Ohio State University, v.61, n.2, mar-abril 1990, pp.181-197. Disponível em: <https://www.jstor.org/stable/1981961> Acesso em: 10 out. 2018.

SMITH COLLEGE. Admission Policy Annoucement. 2 maio 2015. Disponível em: $<$ https://www.smith.edu/studygroup/> Acesso em: 10 out. 2018.

SMITH COLLEGE. Admission Policy Study Group. 2014. Disponível em: <https://www.smith.edu/ president-kathleen-mccartney/letters/2014-15/admission-policy> Acesso em: 10 out. 2018.

SWEET, Leonard I. The Female Seminary Movement and Woman's Mission in Antebellum America. Church History, American Society of Church History, v.54, n.1, mar. 1985, pp.41-55. Disponível em: $<$ http://www.jstor.org/stable/3165749> Acesso em: 10 out. 2018.

TAYLOR, Victoria. Transgender student rejected twice by all-female Smith College urges school to change policy, takes solace in groundswell of support: Focus should be building 'next generation of leaders, not discriminating against them'. New York Daily News. 27 mar 2013. Disponível em: $<$ http://beta.nydailynews.com/news/national/transgender-teen-denied-women-only-college-article-

1.1299840> Acesso em: 10 out. 2018.

WEBER, Shannon. "Womanhood does not reside in documentation”: Queer and feminist student activism for transgender women's inclusion at women's colleges. Journal of Lesbian Studies, Taylor \& Francis, Philadelphia, PA, v.20, n.1, dez 2015, pp.29-45. Disponível em: $<$ https://www.ncbi.nlm.nih.gov/pubmed/26701768> Acesso em: 10 out. 2018.

WONG, Calliope. Make Smith Possible for Trans Women. 15 ago 2012. Disponível em: $<$ https://tmblr.co/ZLxCWuRSOsyn> Acesso em: 10 out. 2018.

WONG, Calliope. Please Read, Share, and Discuss. 22 out 2012. Disponível em: $<$ https://tmblr.co/ZLxCWuVoScqf> Acesso em: 10 out. 2018.

\section{Correspondência}

Marco Aurélio Máximo Prado: Doutor em Psicologia Social pela Pontifícia Universidade Católica de São Paulo. Pós-doutorado pela University of Massachusetts/Amherst com apoio da Fundação Fulbright. Professor junto ao Departamento de Psicologia e Coordenador do Núcleo de Direitos Humanos e Cidadania LGBT+ da Faculdade de Filosofia e Ciências Humanas da Universidade Federal de Minas Gerais. Pesquisador do Programa de Pós-Graduação em Psicologia da Universidade Federal de Minas Gerais e bolsista de produtividade CNPq. Atual presidente da Associação Nacional de Pesquisa e Pós Graduação em Psicologia - ANPEPP.

E-mail: mamprado@gmail.com

Orcid: http://orcid.org/0000-0002-3207-7542 
Antônio Augusto Lemos Rausch: Psicólogo e mestrando em Psicologia pela Universidade Federal de Minas Gerais. Bolsista junto ao Núcleo de Direitos Humanos e Cidadania LGBT+ da Faculdade de Filosofia e Ciências Humanas da Universidade Federal de Minas Gerais. Atualmente pesquisa as relações entre a psicologia e neopentecostalismo nas práticas de conversão sexual em Belo Horizonte/MG.

E-mail: altoniolemos@gmail.com

Orcid: http://orcid.org/0000-0003-0133-6078

Texto publicado em Currículo sem Fronteiras com autorização dos autores 